\title{
PSYCHIATRIC DISORDERS IN THE COURSE OF MULTIPLE SCLEROSIS
}

D0I: 10.36740/WLek202008135

\author{
Magdalena Zając, Patryk Główczyński, Michał Błachut, Karina Agnieszka Badura Brzoza \\ DEPARTMENT OF PSYCHIATRY IN TARNOWSKIE GORY, THE FACULTY OF MEDICAL SCIENCES IN ZABRZE, MEDICAL UNIVERSITY OF SILESIA IN KATOWICE, \\ TARNOWSKIE GORY, POLAND
}

\begin{abstract}
Multiple sclerosis (MS) is an inflammatory and demyelinating disease of the central nervous system of a chronic nature, most often with periods of exacerbation and remission, mainly affecting people between 20-40 years of age, with a slight prevalence of women.

The aim of the study was to collect and analyze materials published in the literature regarding the prevalence and co-occurrence of mental disorders in patients with multiple sclerosis. Current reports show that as many as $75 \%$ of patients with this chronic disease experience various mental disorders, and the incidence of mental diseases - including mood disorders and anxiety disorders - is statistically higher than in the general population.

Conclusions: Depending on the literature, depressive symptoms appear in $6.94 \%-70.1 \%$ of patients with MS. Diagnosis of anxiety disorders affects $11.1 \%$ of patients, while bipolar disorder affects up to $16.2 \%$. Co-occurrence of MS with schizophrenia is estimated at $1.28 \%$. The incidence of other psychoses is $2-4 \%$ in patients with MS. Only in the case of schizophrenia, men with MS are more likely to develop it, while other psychiatric disorders are more common among women. Co-occurrence of mental disorders in the course of multiple sclerosis adversely affects the treatment process and the functioning of patients and their families.
\end{abstract}

KEY WORDS: multiple sclerosis, depression, mental disorders, anxiety, schizophrenia, cognitive impairment

Wiad Lek. 2020;73(8):1780-1784

\section{INTRODUCTION AND THE AIM}

Multiple sclerosis (MS) is one of the most common and incurable inflammatory neurodegenerative diseases with a very complex, multifaceted aetiology. According to statistical data, about 40-60 thousand people suffer from it in Poland, people are diagnosed most often between 20 and 40 years of age [1]. Despite many years of research, it was not possible to indicate the direct cause of the disease. The onset of disease is associated with an abnormal autoimmune response based on genetic predisposition and exposure to environmental factors. The disease is more common in temperate than tropical regions, hence some ethnic factors may be important in its etiology [2]. Characteristic for the course of the disease is the occurrence of relapses - periods of exacerbation and periods of remission (the most common relapsing-remitting form affects about $70 \%$ of patients, others are progressive-relapsing and primary and secondary progressive) $[1,3]$. The chronic course of the disease and its incurability, problems related to incapacity for work, deterioration of social functioning and changes in the central nervous system are conducive to the occurrence of mood disorders and anxiety disorders [1]. It also seems important that the drugs used in multiple sclerosis - corticosteroids and interferon beta may exacerbate the symptoms of mental disorders [4]. In the course of multiple sclerosis, a statistically higher comorbidity of mental disorders was observed compared to the general population, according to some researchers, various mental disorders accompany as much as about $75 \%$ of patients with multiple sclerosis [5].

\section{REVIEW AND DISCUSSION}

\section{DEPRESSIVE DISORDERS}

The analysis of the literature clearly indicates that the most common mental disorders co-occurring in the course of MS are depressive disorders, including depressive episodes and recurrent depressive disorders.

According to the research of Chwastiak and Carson [6, 7], depression may coexist even twice as often as in the population of patients with MS, and depressive symptoms themselves may occur in $40-50 \%$ of patients during one relapse of the disease.

The increasing disability associated with exacerbations of the disease affects the patient's functioning and may be the cause of depressive states. Despite this, some authors indicate that depressive disorders are reported in patients with MS regardless of the degree of disability [8]. Some studies also highlight a significant increase in affective disorders (including depression) in families of patients with multiple sclerosis, which would indicate the involvement of genetic factors in the etiopathogenesis of both diseases. In the aetiology of depressive disorders in the course of multiple sclerosis, one 
should also take into account the impact of the treatment used, e.g. interferon, on the occurrence of mood disorders, and in particular on increasing the tendency to suicidal thoughts $[9,10]$. The disease which is MS causes inflammation and neurodegenerative foci in the brain and spinal cord, and their location has become a point of reflection on the relationship between changes occurring in the CNS and depressive symptoms. Computed tomography study have shown an increase in perfusion in the limbic system among patients with MS and comorbid depression [11]. Other researchers used the magnetic resonance imaging results, but the results turned out to be ambiguous. Occurrence of demyelization foci in the temporal lobes and hippocampus atrophy may correspond to the appearance of depressive disorders in the course of MS. It has not yet been determined whether these changes occur unilaterally or bilaterally, and - if unilaterally - whether they are associated with a specific hemisphere [12-15]. The relationship of depressive disorders with inflammatory changes (not necessarily related to the specific location) was also shown in Rossi's studies in 2017 [16]. He has emphasized the subclinical nature of mood disorders, with a simultaneous tendency to lower the severity of depression and anxiety disorders during the extinction of an active inflammatory process in the nervous system. A lot of information regarding the association of MS with depressive disorders was provided by two large Canadian retrospective studies conducted by Marrie et al. The first was a study in 1995 - 2005 on a group of 44,452 patients with multiple sclerosis (the control group had 220,452). It showed an incidence of depressive disorders per year of $0.98 \%$ $(0.94 \%$ women; $1.02 \%$ men) with a result of $0.72 \%$ in the control group, which meant $71 \%$ more frequent diagnoses of depression in the group of patients on SM. In the available literature, data on the prevalence of depression in MS range from $4.98 \%$ to $58.9 \%$ (20.1\% on average) among the patients studied. The comorbidity of depression in women with MS is $59 \%$ higher than in the control group and $93 \%$ higher in the men group than in the control group. The results clearly indicate $26 \%$ higher prevalence of depression among women than men in the population of patients with MS [17]. In another publication by Marrie et al. From 2016 [18], the study covered a group of 23,382 patients diagnosed with multiple sclerosis whose data was in the health care database of four Canadian provinces. The comorbidity of mental illness (depression, schizophrenia, anxiety disorder, bipolar disorder) and somatic illness with a control group was compared. It has been shown that these mental diseases are more common in patients with MS than in the control group. Depression disorders were the most common comorbidities - in 19.1\% of respondents (in the control group 9.38\%). The risk of suicidal behaviour was 2 to 7 times higher than in the general population, what is more - in $15 \%$ of patients committing suicide, symptoms of depression in the period preceding the act were reported [19]. Individual studies on the frequency of suicide attempts in groups of patients with MS have not been and are not conclusive. Lunde et al. [20] in a Norwegian population study showed that about $1.4 \%$ of MS patients had at least one suicide attempt. A French study from the same year under the direction of Kalson Ray [21] showed a lower trend, at $0.17 \%$, while the Hungarian 2016 analysis indicated a frequency of 3.89\% [22]. Some authors also draw attention to the fact that patients with multiple sclerosis who coexist with depressive disorders exhibit cognitive impairment, a higher degree of disability, and respond less well to the treatment of the underlying disease [1]. In addition, Tauil et al. [23] showed that patients with longer disease duration are more likely to experience depression.

\section{ANXIETY DISORDERS}

Chronic disease such as MS can also be a source of various anxiety disorders. The mutual relationship of growing anxiety and depressive symptoms is important [3].

Retrospective studies of the team led by Marrie et al. Provided a lot of information unambiguously indicating the coexistence of anxiety disorders with MS. The first study published in 2015 showed an incidence of $0.64 \%$ (with a result of $0.42 \%$ in the control group; $0.74 \%$ women; $0.33 \%$ men), which indicated as much as $42 \%$ greater recognition compared to groups of patients not burdened with multiple sclerosis. The prevalence of anxiety disorders is estimated at $1.2 \%$ to $44.6 \%$, on average $8.7 \%$ in the group of people with MS. More often anxiety disorders are recorded among women - about $10 \%$, while among men $4.9 \%$ of patients [17] An earlier study under the same management in 2009 showed that the diagnosis of anxiety disorders ranges from $1.24 \%$ to $36 \%$ of respondents. They were observed in $2.72 \%$ of respondents at the time of appearance of the first symptoms of the disease to $6.23 \%$, when the diagnosis of multiple sclerosis was made [24].

The 2016 study has also confirmed that among MS patients anxiety disorders occur more frequently than in the compared control group and affect $11.1 \%$ of patients (2.594 out of 23.3382 patients). In the control group, anxiety disorders were diagnosed in almost $7 \%$ of patients (6.89\%). Anxiety disorders were more common in women (12.3\%) than in men (8.12\%) among MS patients [18].

A French study led by Gay [25] also pointed to the relationship between anxiety and depression in MS patients, stating that anxiety may be a harbinger of depression. Pham et al. [26] in their studies, using the HADS scale, showed that as many as $30 \%$ of patients with MS revealed anxiety disorders. In addition, it was noted that higher education correlated with a lower level of perceived anxiety, and a high level of anxiety was associated with a significant deterioration in the quality of life. It is surprising that the level of anxiety is not correlated with the degree of disability, however, the vision of worsening the underlying disease leads to an increase in its level [27].

\section{COGNITIVE DISORDERS}

Along with increasing anxiety, other disorders are also correlated. It was estimated that even $65 \%$ of patients with diagnosed multiple sclerosis suffer from cognitive impairment. 
Importantly, this dysfunction also applies to both isolated radiological syndrome (RIS) [28] and isolated clinical symptom complex (CIS) [29]. The most common cognitive deficits in patients with MS are episodic memory loss and a decrease in cognitive processing, with disturbances in spatial-visual orientation and verbal fluidity. [thirty]

Cognitive decline affects the early stages of the underlying disease, but the disorders vary qualitatively depending on the form of MS. Importantly, patients with high levels of anxiety have cognitive self-perception disorders [31].

Baird et al. Study [32] pointed to the relationship between cognitive ability and age of patients with MS. The elderly affected by this chronic disease had poorer visual memory and cognitive processing speed than younger patients. Sacco et al. [33] examined patients with relapsing-remitting in terms of volume of brain structures and cognitive deficits. It was shown that the patients showed a greater atrophy of gray matter, white matter and hippocampus (left and right) than the control group of healthy people. Compared with MS patients with cognitive deficits, the lesions appear to be greater than those with no disorder at comparable white matter decline. Similarly, Daams [34] in 2016 showed that patients with multiple sclerosis present extensive atrophy and damage up to $75 \%$ of the studied white matter. Interestingly, the imaging abnormalities were twice as strong in patients with cognitive deficits than in patients with these functions.

Many difficulties arise in the unequivocal assessment of whether cognitive decline is actually associated with high levels of anxiety or whether it is a primary symptom in multiple sclerosis itself.

\section{BIPOLAR DISORDERS}

An analysis of the research of Chwasiak and Ehde [8] proves that the symptoms of bipolar disorder may occur even twice as often in patients with multiple sclerosis as compared to the general population. Manic states have been observed in MS patients, but some researchers believe that they could have been the result of inadequate diagnostics and treatment, or a consequence of steroid pharmacotherapy. Attempts have been made to explain emotional lability by damaging the pathways connecting the frontal lobes to the limbic system.

In the study of Marrie et al. [17], the prevalence of bipolar disorder throughout life was between 0 and $16.2 \%$. An earlier 2013 population study showed a $5.83 \%$ incidence rate of bipolar disorder among MS patients [35]. Interesting conclusions regarding the epidemiology of childhood MS and the comorbidity of bipolar disorder were established by Goretti [36], amounting to 3.57\%.

In the 2016 Marrie study [18], a co-occurrence of bipolar disorder was found in a smaller percentage of adults tested, because $3.15 \%$ of patients ( 736 out of 22,382 patients) with multiple sclerosis. In a control population of 116.638 patients, bipolar disorder was diagnosed in 1.973 patients, which gives a prevalence of $1.69 \%$. In both populations, bipolar disorder is more common in women and affects respectively $3.52 \%$ of women with multiple sclerosis and $1.89 \%$ of women in the control population (for men it is $2.69 \%$ and $1.19 \%$, respectively).

\section{PSYCHOTIC DISORDERS}

While the presence of depressive or anxiety disorders in the course of multiple sclerosis seems to be understandable, the relationship of the disease to psychotic disorders is not so obvious. Although bipolar disorder and schizophrenia are separate disease entities, they have some similarities, such as the nature of changes in the central nervous system [37]. Some hypotheses also assume a common pathogenetic pathway of both diseases, consisting in the occurrence of a disorder of the body's immunity mechanisms and an inflammatory reaction [38]. It seems interesting that both disorders affect young adults. Multiple sclerosis often manifests in adolescents between 15 and 20 years old, while schizophrenia occurs in people over the age of 18 years. [39] Also the genetic link between the two diseases is also of interest to researchers. Identical (homozygotic) twins have consistently high compliance rates for both of these diseases. These compliance rates for identical twins range around $30-80 \%$ for MS and about 50 to $60 \%$ for schizophrenia. What is important, heterozygotic twins have a significantly lower ratio (5-10\%) [40,41]. A study on the coexistence of multiple sclerosis and schizophrenia conducted in the Canadian population showed that the incidence of schizophrenia was $0.06 \%$ among MS patients (including $0.072 \%$ in women and $0.011 \%$ in men). The prevalence of schizophrenia in the group of patients with MS was $1.28 \%$ (1.22\% in men. $0.89 \%$ in women). It was surprising that, unlike other mental illnesses analyzed, the coexistence of schizophrenia in men was higher than in women, as was also shown in other studies [17].

A 2016 study led by Marrie [18] showed that the diagnosis of schizophrenia affects $1.07 \%$ of patients diagnosed with MS (251 out of 22.282 patients), while in the control group reflecting the general population, the prevalence is $0.81 \%$ (947 out of 116.638 patients ). According to the results obtained, both among patients with MS and in the control group, schizophrenia is the only mental disease that occurs more often in men than women, and affects respectively $1.52 \%$ men and $0.9 \%$ women with MS and $0.95 \%$ men, and $0.76 \%$ of women in the control group.

Older studies from 2010 showed a different coincidence trend. The Mexican analysis determined the prevalence of schizophrenia at $0.06 \%$ at the onset of the first symptoms of MS and at $0.08 \%$ at the time of diagnosis of multiple sclerosis [42]. In Eaton's publication [43], it was shown that the incidence of schizophrenia in the population of patients with MS does not differ compared to the general population. Over the years, researchers have linked the occurrence of MS psychotic disorders with the inflammatory and neurodegenerative process that occurs in the essence of periventricular white matter, frontotemporal and temporal issues in patients with MS, but as of today there is no clear 
evidence to show such a relationship[44]. In Swedish reports, the authors point out that psychotic disorders do not have to increase the risk of developing schizophrenia [45].

\section{CONCLUSIONS}

An analysis of the literature indicates a diverse and frequent occurrence of mental disorders among patients with multiple sclerosis. The very diagnosis of a chronic disease is a significant burden for patients, and the additional problems arising in its course affect its comfort of life, daily functioning and relationships with the environment. The coexistence of neurological symptoms and mental disorders worsens the quality of life of both MS patients and their families, and also poses a therapeutic challenge for clinicians. It is worth noting that the treatment of patients with MS should not be focused solely on the treatment of the underlying disease, but requires the doctor's attention to stabilize the mental state, care for the patient's mental condition, by motivating to undertake psychiatric treatment and psychotherapy.

\section{REFERENCES}

1. Gałązka-Sobotka M, Błaszczyk M, Drapała A, et al. Społecznoekonomiczne skutki Stwardnienia Rozsianego (SM) w Polsce (Biała księga). Warszawa: Uczelnia Łazarskiego, 2014.

2. Rosati G.: The prevalence of multiple sclerosis in the world: an update. Neurol Scien. 2001;22(2):117-139.

3. Feinstein A, Magalhaes S, Richard J.R, Audet B, MooreC. The link between multiple sclerosis and depression. Nat Rev Neurol. 2014;10(9):507-17.

4. Losy J, Bartosik-Psujek H, Członkowska A, et al. Leczenie stwardnienia rozsianego. Zalecenia Polskiego Towarzystwa Neurologicznego. Pol Przegl Neurol. 2016;12(2):80-95.

5. Florkowski A, Chmielewski H, Gałecki P. Zaburzenia psychiczne w stwardnieniu rozsianym. Aktual Neurol. 2009;9(4):264-266.

6. Chwastiak L, Ehde DM. Psychiatric issues in multiple sclerosis. Psychiatr Clin North Am. 2007;30:803-817.

7. Carson A, Zeman A, Phil M, Myles L, Sharpe M. Neurology and neurosurgery. Levenson J.L. (red.): The American Psychiatric Publishing Textbook of Psychosomatic Medicine. American Psychiatric Publishing, Inc., Washington DC 2005.

8. Zorzon M, de Masi R, Nasuelli D et al. Depression and anxiety in multiple sclerosis. A clinical and MRI study in 95 subjects. J. Neurol. 2001;248:416421.

9. Klapper J. Interferon beta treatment of multiple sclerosis. Mult Scler Relat Disord. 2018;26:124-156.

10. Marrie R, Walld R, Bolton J, et al. Physical comorbidities increase the risk of psychiatric comorbidity in immune-mediated inflammatory disease. Gen Hosp Psychiatry. 2018;51:71-78.

11. Sabatini U, Pozzilli C, Pantano P, et al. Involvement of the limbic system in multiple sclerosis patients with depressive disorders. Biol Psychiatry 1996;39:970-975.

12. Bakshi R, Czarnecki D, Shaikh Z, Priore R, Janardhan V, Kaliszky Z, KinkelP. Brain MRI lesions and atrophy are related to depression in multiple sclerosis. Neuroreport 2000;11:1153-1158.

13. Zorzon M, Zivadinov R, Nasuelli D, et al. Depressive symptoms and MRI changes in multiple sclerosis. Eur J Neurol. 2002;9:491-496.

14. Berg D, Supprian T, Thomae J, et al. Lesion pattern in patients with multiple sclerosis and depression. Mult Scler. 2000;6:156-162.
15. Gold S, O'Connor M, Gill R, et al. Detection of altered hippocampal morphology in multiple sclerosis associated depression using automated surface mesh modeling. Hum Brain Mapp. 2014;35:30-37.

16. Rossi S, Studer V. Neuroinflammation drives anxiety and depression in relapsing-remitting multiple sclerosis. Neurology 2017;89(13):13381347.

17. Marrie R, Fisk J, Tremlett H, et al. Differences in the burden of psychiatric comorbidity in MS vs the general population"Neurology 2015;85:19721979.

18. Marrie R, Patten S, TremlettH, et al. Sex differences in comorbidity at diagnosis of multiple sclerosis. Neurology 2016;86:1279-1286.

19. Florkowski A, Chmielewski H, Gałecki P. Zaburzenia psychiczne w stwardnieniu rozsianym. Aktualności Neurologiczne 2009;9(4):264-266.

20. Lunde H, Assmus J, Kjell-Morten M, Bo L, Grytten N. Survival and cause of death in multiple sclerosis: a 60-year longitudinal population study. J Neurol Neurosurg Psychiatry 2017;88:621-625.

21. Kalson-Ray S, Edan G, Leray E. An excessive risk of suicide may no longer be a reality for multiple sclerosis patients. Multiple Scler. 2017;23:864871.

22. Sandi D, Zsiros V, Fuvesi J, et al. Mortality in Hungarian patients with multiple sclerosis between 1993 and 2013. J Neurol Sci. 2016;367:329332

23. Tauil C, Grippe T, Dias R, Dias-Carneiro R, Carneiro N, Aguilar A. Suicidal ideation, anxiety, and depression in patients with multiple sclerosis. Arq Neuro-Psiquiatr. 2018;76:296-301.

24. Marrie R, Horwitz R, Cutter G. The burden of mental comorbidity in multiple sclerosis: Frequent, underdiagnosed, and under-treated. Mult Scler 2009;15:385-392.

25. Gay M, Bungener, C, Thomas S, et al. Anxiety, emotional processing and depression in people with multiple sclerosis. BMC Neurol 2017;17:43.

26. Pham T, Jetté N, Bulloch A, Burton J, Wiebe S, Patten S. The prevalence of anxiety and associated factors in persons with multiple sclerosis. Mult Scler Relat Disord. 2018;19:35-39.

27. Janssens A, van Doorn P, de Boer J, van der Meche F, Passchier J, Hintzen R. Perception of prognostic risk in patients with multiple sclerosis: the relationship with anxiety, depression, and disease-related distress. J Clin Epidemiol. 2004;57(2):180-186.

28. Labiano-Fontcuberta A, Martínez-Ginés M, Aladro Y. A comparison study of cognitive deficits in radiologically and clinically isolated syndromes. Mult Scler 2016;22:250-253.

29. Hynčicová E, Vyhnálek M, Kalina A, et al. Cognitive impairment and structural brain changes in patients with clinically isolated syndrome at high risk for multiple sclerosis. J Neurol. 2017;264:482-493.

30. Sumowski J, Benedict R, Enzinger C, et al. Cognition in multiple sclerosis: State of the field and priorities for the future. Neurology. 2018;90(6):278288.

31. Bruce J, Bruce A. Self-reported memory problems in multiple sclerosis: Influence of psychiatric status and normative dissociative experiences. Arch Clin Neuropsychol. 2010;25(1) :39-48.

32. Baird J, Cederberg K, Sikes E, Jeng B, Sasaki J, Sandroff B, Motl R. Changes in Cognitive Performance With Age in Adults With Multiple Sclerosis. Cogn Behav Neurol. 2019;32(3):201-207.

33. Sacco R, Bisecco A. Cognitive impairment and memory disorders in relapsing-remitting multiple sclerosis: the role of white matter, gray matter and hippocampus. J Neurol. 2015;262:1691-1697.

34. Daams M, Steenwijk M, Shoonheim M, et al. Multi-parametric structural magnetic resonance imaging in relation to cognitive dysfunction in long-standing multiple sclerosis. Mult Scler. 2016;22(5):608-619. 
35. Marrie R, Fisk J, Yu B, et al. Mental comorbidity and multiple sclerosis: Validating administrative data to support population-based surveillance. BMC Neurol 2013;13:16.

36. Goretti B, Ghezzi A, Portaccio E, Lori S, Zipoli V, Razzolini L, Moiola L. Psychosocial issue in children and adolescents with multiple sclerosis. Neurol Sci 2010;31:467-470.

37. Altamura A, Buoli M, Serati M. Duration of illness and duration of untreated illness in relation to drug response in psychiatric disorders. Neuropsychiatry. 2011;1:81-90.

38. Kunz M, Ceresér K, Goi P, Fries G, Teixeira A, Fernandes B. Serum levels of IL6, IL10 and TNFalpha in patients with bipolar disorder and schizophrenia: Differences in pro- and anti-inflammatory balance. Rev Bras Psiquiatr. 2011;33:268-274.

39. Benros M, Mortensen P, Nielsen P, Nordentoft M, Eaton W, Dalton S. Autoimmune diseases and infections as risk factors for schizophrenia. Ann NY Acad Sci. 2012;1262:56-66.

40. Andreassen 0 , Harbo H, Wang $\mathrm{Y}$, et al. Genetic pleiotropy between multiple sclerosis and schizophrenia but not bipolar disorder: Differential involvement of immune-related gene loci. Mol Psychiatry. 2015;20:207-214.

41. Picchioni M, Toulopoulou T. 4 Genetic determinants of the vulnerability to psychosis: Findings from twin studies.In: Fusar-Poli P, Borgwardt SJ, McGuir P (eds) Vulnerability to Psychosis: From Neurosciences to Psychopathology. East Sussext, UK: Psychology Press 2013, p. 41.

42. Espinola-Nadurille M, Colin-Piana R, Bermudez J, Lopez-Gomez M, Flores J. Arrambide G, Corona T. Mental disorders in Mexican patients with multiple sclerosis. J Neuropsychiatry Clin Neurosci 2010;22:63-69.

43. Eaton W, Pedersen M, Nielsen P, Mortensen P. Autoimmune diseases, bipolar disorder, and non-affective psychosis. Bipolar Disord. 2010;2:638-646.
44. Patten S, Svenson L, Metz L. Psychotic disorders in MS: population-based evidence of an association. Neurology 2005;65:1123-5.

45. Johansson V, Lundholm C, Hillert J, Masterman T, Lichtenstein P, Landen M, Hultman C. Multiple sclerosis and psychiatric disorders: comorbidity and sibling risk in a nationwide swedish cohort. Mult Scler. 2014;20:1881-91.

\section{ORCID and contributionship}

Magdalena Zając - 0000-0002-0184-5422 B, D,F

Patryk Główczyński - 0000-0002-0140-0917 B, D, F

Michał Błachut - 0000-0002-4438-2376 A, F

Karina Agnieszka Badura Brzoza - 0000-0002-1810-9018

\section{Conflict of interest}

Authors declare no conflict of interest

\section{CORRESPONDING AUTHOR Karina Agnieszka Badura Brzoza}

Katedra i Oddział Kliniczny Psychiatrii w Tarnowskich Górach, Pyskowicka 49, 42-612, Tarnowskie Góry, Poland; tel. 6068344356

e-mail:kbbrzoza@sum.edu.pl

Received: 29.04 .2020

Revised: 21.06 .2020 